fortified by a liberal dietary, by the use of cod-liver oil and by climatic treatment.

Dr. Theodore Williams, at the express wish of the president of the college, proceeded to sketch the evolution of the treatment of consumption as it had come under his own cognisance during his nearly fifty years of professional experience. He spoke of the effects of climate, and especially of that of high altitudes; then of the open-air life which had first been advocated in England by Bodington and Henry MacCormac, and was now accepted as essential in cases of tubercular disease. Dr. Williams had personally studied the climates most advantageous for the treatment of consumption in the New and the Old Worlds, and had given a full trial to mountain climates, having recorded their effects on more than 400 of his private patients, and studied the results of the diminished barometric pressure, of the diathermancy of the air, and of the asepticity, or freedom from pathogenic germs, which are characteristic of high-altitude climates.

$\mathrm{He}$ found the effects on selected cases of chronic tuberculosis remarkable: many symptoms vanished, and muscular power increased largely, while the local improvement was even more striking, and in many early cases of consolidation the disappearance of physical signs was so complete that the physician had to refer to his notes to discover which lung was originally attacked! In fact, the highaltitude cases yielded the most favourable results of all his statistics, and, what is more important, the fewest relapses.

He then noticed the establishment and spread of sanatoria all over the world, and said that in Germany alone the insurance societies now maintain more than $\mathrm{I} 6,000$ beds for the working classes; and he directed attention to the methods pursued, including rest, with or without Liegehalle, good feeding, graduated exercise, and labour supervised to meet individual requirements, which have all been tried at different sanatoria, giving the results achieved thereby. $\mathrm{He}$ described the system pursued at some of the best English institutions, where the patients with limited tuberculous pulmonary lesions, when removed to thoroughly hygienic surroundings and compelled to lead a healthy life, their food, exercise, and rests being under minute skilled direction, may slowly and gradually recover, and, losing symptoms, be able to return home to active working life, ready and able to instruct those around them in the gospel of fresh air and wholesome living.

But Dr. Williams emphasised the need for discovering and treating early cases of the disease, and though agreeing in the general truth of the curability of consumption, he felt obliged to except the acute cases, which, however, fortunately form a very small percentage of the whole.

$\mathrm{He}$ contended that the pressing need is for more hospitals for consumption-England had been a leader in establishing these, and now it is recognised that the consumption hospital is required as a centre from which to draft off cases suitable for sanatoria, as well as for the treatment of more advanced and acute cases, which are thus isolated from the rest of the population and prevented from becoming centres of infection.

Dr. Theodore Williams spoke of the modern treatment of consumption by anti-tuberculous serums and vaccines, and gave the experience of others and of himself, concluding by the remark that everything points to the necessity for further investigation, and that such investigation can be best carried on in hospitals and sanatoria, where trained observers minutely watch the effect of tuberculin on the patient's system and control the inoculations and their results. He summed up with a bird's-eye view of the present state of the crusade against tuberculosis in this country and our means of pursuing the fight.

$\mathrm{He}$ reminded his audience of what had already been done by the blessed agencies of prevention, such as improved drainage, more cubic space, and less overcrowding, better food and more of it, more air and sunlight. cleanliness of house and person, and increased opportunities for play and exercise, and how, mainly by these means, the phthisis mortality had been reduced two-thirds in fifty years.

NO. 2 I92. VOL. 887
A good town-planning scheme should prove a fine weapon in the hands of the combatants. Education of all classes, including the children, must be promoted, and that with the tuberculosis exhibitions and popular lectures and tracts which now permeate and enlighten the country, wil be found to be trusty armour and show the people how they can help themselves.

Prevention is naturally what is to be aimed at; but for the consumptives who are now among us are needed as links in the chain :-

(I) Well-equipped consumption hospitals to receive and isolate acute and advanced cases.

(2) The dispensary system, introduced by Dr. Philip, and now at work in several metropolitan boroughs, which, with the out-patient departments of consumption hospitals, can classify the patients, visiting them and contacts in their own homes, and connecting them with local government and philanthropic agencies.

(3) The sanatorium, and especially those institutions which make a feature of preparing the patient by various grades of labour for return to a workaday world.

(4) Labour colonies and exchanges to assist in the rehabilitation of those who have been smitten with the disease, or may be more liable to reinfection, or may require the safeguard of a changed and more healthy occupation.

The task of further reducing, and finally abolishing, tuberculosis is not a hopeless one, but it does not lie wholly with the doctors. It lies also with those who have it in their power to remove and lessen the principal causes of tuberculosis, viz. the overcrowding of our cities, the want of open spaces and of ventilation, the insanitary houses, the disgusting habit of spitting, and the lack of a good supply of water and of pure milk. Philanthropists, together with local government authorities administering under our Minister of Health, might remedy these defects and ensure that the number of phthisis cases should be in future comparatively small.

The great Harvey would smile with pleasure as he realised our successive advances in knowledge and the attempts to remedy our deficiencies, and he might well receive our laurel crown as the leader who showed the way to those who are now searching out the secrets of nature by way of experiment.

\section{UNIVERSITY EDUCATION IN ENGLAND AND WALES.}

A TTENTION has been directed already (NATURE, September 2I, vol. Ixxxvii., p. 407) to the Blue-book containing the reports for the year 1909-10 from those universities and university colleges in Great Britain which participate in the Parliamentary grant for university colleges. In the notes referred to, information was given as to the amount of the Treasury grant, particulars concerning the incomes of the various colleges, and similar data.

An introductory report by the Board of Education, with which the volume opens, contains much that deserves careful study by all who are interested in the progress of higher education. A number of extracts from this prefatory memorandum are subjoined.

The weakness of the appeal which university education makes in the present day to the imagination of the wealthy finds its counterpart in the apathy of the public at large, and this apathy is only too frequently reflected in the attitude of the local authorities. Some of the most important of these give far less than their proper share of support to the universities, and in one or two instances the maintenance at their present level of the grants made by local education authorities has been endangered. On the other hand, in two instances there has been a notable increase in the amount of the support received from this source. As the result of representations made by the Right Hon. Joseph Chamberlain, M.P., the Chancellor of the University, the City of Birmingham has promised to increase 
its grant in aid of the University of Birmingham from $\frac{1}{2} d$. to $\mathrm{I} d$. rate. The exact amount of increased support thus given to the University is, however, for the moment uncertain, because the University has been required by the municipality to devote an as yet indeterminable portion of the additional grant to the establishment of maintenance allowances and scholarships to poor students. Since the fees paid by students never equal the cost of the education they receive, it follows that the net amount of the increased aid to the University will be something less than the difference between the gross increase and the sum devoted to maintenance allowances and scholarships. If, as there is reason to hope will be the case, the grant is continued at the higher level for future years, the extension of the boundaries of the city will lead to a further increase in the amount received by the University unless this additional income has to be expended on scholarships or bursaries. The Corporation of Newcastle-upon-Tyne has recently made an additional grant of $1500 l$. a year for five years to Armstrong College. This additional grant is the more noteworthy because it has been made for the special purpose of developing the faculty of arts, a faculty which does not, as a rule, appeal so directly to local sympathies as do the faculties of pure and applied science.

The problem of university education in the metropolis does not grow easier as time advances; the need for that help and guidance which only a well-organised university can afford increases yearly. The many independent institutions and authorities working in the field of operations are conscious, each in its own way, of the growing demand for instruction of a high order, and of the urgent necessity for increased maans of providing it, and it is not to be wondered at if they attack the problem as best they may, without considering too closely the effects of their action upon their neighbours. Yet no satisfactory issue is possible on these lines. The Board is endeavouring for the moment to avoid encouraging this confusion, but nothing really far-reaching can be attempted until after the Royal Commission appointed in 1909 has completed its labours.

This need for a proper scheme of coordination is perhaps especially urgent in the case of higher technological and professional work; it is not confined to London. Until the problem has been adequately dealt with, it is almost impossible to deal wisely with even the most urgent claims for further development. Yet there is undoubtedly a great need for considerable further provision of the highest type of instruction. The fifth annual report of the British Science Guild contains certain rough comparisons between the number of properly equipped day students attending the technische Hochschulen in Germany and the numbers of day students doing work of a kind more or less comparable in this country. The comparison shows that after making full allowance for the larger population of Germany, there are more than twice as many such students in Germany as in Great Britain and Ireland. If the inquiry could be more exact, and if only those students in this country were included who had received the same amount of previous general education, and were giving the whole of their time to higher technical studies, it is certain that the comparison would be even less favourable.

But if the problem in regard to technology is to discover how to make a wise increase in the amount of provision without the incidental waste which comes from unnecessary overlapping between competing institutions, the problem in connection with medical education is quite different. What is needed here is concentration and coordination of effort and the greater efficiency that will then alone be possible. There is probably more than sufficient provision made for medical education in these islands; it is a question whether, even now, after years of shrinkage in the numbers of men entering the medical profession, the output is not still in excess of the national needs. Nowhere is this excess of provision more evident than in the metropolis. The difficulties inherent in the position are obvious, particularly at the present moment, when public opinion has not yet been fully informed as to the true relationship between the hospital and the medical school, or as to the invaluable services which a progressive school renders not only to the treatment of the sick poor, but also to the national medical service. To the closeness of this relationship, on the other hand, is due the facilities for access to clinical study which London offers to a greater degree than any place in the world. Any change which endangered this advantage would be very dearly bought.

Of the twenty-three-general medical schools in England, all but five (including Oxford and Cambridge) have now applied to the Board for grants in aid of the instruction they give. It is hoped it may be possible to include in the next volume of these reports returns from the medical schools in receipt of grant from the Board analogous to those now received from universities and university colleges in receipt of aid from the Exchequer. It is not unreasonable to anticipate that these reports will afford a valuable basis for a general consideration of the many problems in regard to medical education existing at the present time.

Reterence was made in the introductory report last year to the tutorial classes which have been established on the initiative of the Workers' Educational Association. Although, as explained in that report, the education given in these classes cannot properly be called university education, yet the universities have throughout been so closely connected with their organisation that some further reference to them seems not inappropriate. During the current session there are nearly seventy of these classes at work, or nearly double the number in existence last session. The rapid growth of the classes continues to afford undoubted evidence of the extent to which they are meeting a real need. Further development was made last year, when a summer school was established for the first time. The school was held in Oxford during July and August, and was intended for students who had attended tutorial classes during the previous session. As students could only remain for a week, or at most a fortnight, the lectures and instruction for each week were arranged to deal with a particular subject or group of subjects. An important part of the students' work consisted in writing essays, which were subsequently read and discussed with special tutors. The arrangements were necessarily somewhat experimental, but there seems little doubt that the students greatly appreciated the establishment of the school, and derived much benefit from it. Grants were paid by the Board of Education in aid of the classes held during the session 1909-10, and also in respect of the summer school. During the session the Board arranged for a special inspection of some of the classes, and the report was subsequently made public. The report fully confirmed the high opinion already existing as to the value of the classes.

The accompanying table presents an analysis of the students under instruction in England and Wales during the academical year $1909-10$. The revised form in which the returns of students has been compiled by the universities has rendered it possible to make this table more detailed than before. The table also gives more accurate figures than have been hitherto available as to the number of students being prepared by university institutions for matriculation examinations.

The number of part-time students of all kinds in England reaches the large figure of more than 13,700 , or more than half again as large as the number of whole-time day students. Only about 1200 of these were reading for degrees or attending post-graduate courses. A considerable proportion of the remainder only attended short courses; but even so it is evident that there is as yet no sign of any relative decrease in the demand being made upon the universities for work which, excellent and useful as it is, cannot be described as university work in the strict sense of the term. It is to be hoped that as time goes on, and as the secondary schools of the country make their influence more clearly felt, the relative growth in the number of fulltime students properly equipped for university studies will increase.

The number of day students under seventeen is but 2.5 per cent. of the total, and the number under eighteen is less than ro per cent. of the whole number of day students. These figures are encouraging, and as compared with the figures for ten years ago, if these could be obtained, would probably show an increase in the age at which the majority of the students are entering upon university courses now. In proportion as the length of school life in the secondary schools increases, the percentage of day students entering the universities under

NO. 2 I92, VOL. 887 
Analysis of Returns of Students under Instruction, 1909-10.

\begin{tabular}{|c|c|c|c|c|c|c|c|c|c|c|c|c|c|c|c|c|c|}
\hline \multirow{3}{*}{\multicolumn{5}{|c|}{ Name of University or College }} & \multicolumn{9}{|c|}{ Full-time Students } & \multirow{3}{*}{ 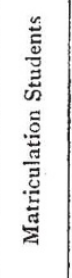 } & \multirow{3}{*}{ 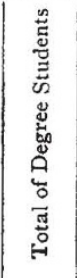 } & \multirow{3}{*}{ 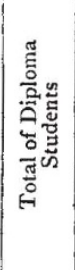 } & \multirow{3}{*}{ 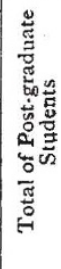 } \\
\hline & & & & & \multicolumn{3}{|c|}{ Degrees } & \multicolumn{3}{|c|}{$\begin{array}{c}\text { Diplomas } \\
\text { (Non-graduate) }\end{array}$} & \multirow{2}{*}{ 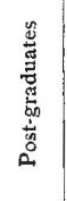 } & \multirow{2}{*}{ 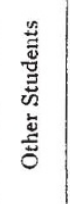 } & \multirow{2}{*}{ 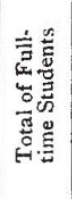 } & & & & \\
\hline & & & & & 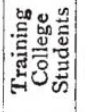 & 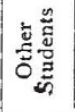 & 胥 & 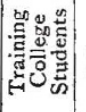 & 总蒡 & $\stackrel{\text { जूँ }}{\stackrel{0}{\leftrightarrow}}$ & & & & & & & \\
\hline \multicolumn{5}{|c|}{ ENGLAND. } & & 414 & & & $8 I$ & & & & & & & & \\
\hline & Bristol University $\quad \ldots$ & $\cdots$ & $\begin{array}{l}\cdots \\
\cdots\end{array}$ & $\cdots$ & 57 & $\begin{array}{l}4 \times 4 \\
197\end{array}$ & 254 & $\begin{array}{l}34 \\
195\end{array}$ & 91 & $\begin{array}{l}215 \\
286\end{array}$ & $\begin{array}{l}30 \\
14\end{array}$ & $\begin{array}{r}50 \\
4\end{array}$ & $\begin{array}{l}022 \\
55^{8}\end{array}$ & 27 & $\begin{array}{l}5^{27} \\
260\end{array}$ & $\begin{array}{l}215 \\
322\end{array}$ & $\begin{array}{l}60 \\
32\end{array}$ \\
\hline & Leeds University $\quad \ldots$ & $\ldots$ & $\ldots$ & $\ldots$ & I4I & 285 & 426 & 6 & 106 & 113 & 20 & 148 & 706 & - & 454 & 132 & 37 \\
\hline & Liverpool University ... & $\ldots$ & $\ldots$ & $\ldots$ & 251 & 432 & 683 & 4 & 185 & 189 & 123 & I3 & 1008 & - & 703 & 209 & I53 \\
\hline & Manchester University & $\cdots$ & $\ldots$ & $\ldots$ & 204 & 736 & 940 & $55^{1}$ & Iro & 165 & 155 & 154 & I4I 4 & $3 \mathrm{I}$ & 1012 & 166 & 198 \\
\hline & $\begin{array}{l}\text { Sheffield University } \ldots \\
\text { London University :-- }\end{array}$ & $\cdots$ & $\cdots$ & $\cdots$ & 79 & 123 & 202 & I & 67 & $6 \ddot{8}$ & 6 & 69 & 345 & 5 & 2 II & 244 & I8 \\
\hline & University College ... & $\ldots$ & $\cdots$ & $\ldots$ & 90 & 406 & 496 & - & 71 & $7 \mathrm{I}$ & 152 & 178 & 897 & I7 & $57 \mathrm{I}$ & 84 & 423 \\
\hline & King's College ... $\quad \ldots$ & $\cdots$ & $\cdots$ & $\cdots$ & 88 & 264 & 352 & - & 137 & 137 & 43 & 14 & 546 & 79 & 472 & 198 & 134 \\
\hline & Bedford College $\quad \ldots$ & $\ldots$ & $\ldots$ & $\ldots$ & 45 & I 43 & 188 & - & 18 & 18 & 29 & Io & 245 & 16 & 188 & 18 & 38 \\
\hline & School of Economics ... & $\cdots$ & $\ldots$ & $\ldots$ & - & 70 & 70 & - & $\mathbf{I}$ & I & 32 & 8o & 183 & - & I $8 \mathrm{I}$ & 2 & 95 \\
\hline & $\begin{array}{l}\text { East London College ... } \\
\text { Durham University :- }\end{array}$ & $\cdots$ & $\cdots$ & $\ldots$ & 46 & 110 & 156 & 一 & - & - & 2 & - & $15^{8}$ & $63^{2}$ & 278 & - & $2 \mathrm{I}$ \\
\hline & Newcastle, Armstrong Colle & & $\cdots$ & $\cdots$ & 90 & I6x & 251 & I Io & 48 & 158 & 6 & 102 & 517 & - & $25 \mathrm{I}$ & 158 & II \\
\hline & Nottingham University Coll & ege & $\ldots$ & $\ldots$ & 61 & 65 & 126 & 90 & 24 & II 4 & 3 & - & 243 & 28 & 134 & 295 & 4 \\
\hline 14. & Reading University College & $\cdots$ & $\ldots$ & $\cdots$ & 54 & 6I & 115 & 76 & $5^{I}$ & 127 & II & 71 & 324 & 13 & 122 & 127 & 12 \\
\hline 15. & Southampton, Hartley Univ & ersity $C$ & college & $\cdots$ & 42 & 46 & 88 & 106 & 9 & 115 & 5 & - & 208 & 9 & $9^{8}$ & × 57 & I3 \\
\hline \multirow[t]{2}{*}{ I6. } & \multicolumn{2}{|c|}{ Totals-England } & $\cdots$ & $\cdots$ & $136 \mathrm{x}$ & $35^{\mathrm{I}} 3$ & 4874 & 777 & 999 & 1776 & $63 x$ & 893 & 8174 & 288 & 5462 & 2327 & 1255 \\
\hline & $\begin{array}{l}\text { WaLES. } \\
\text { University of Wales :- }\end{array}$ & & & & & & & & & & & & & & & & \\
\hline & Aberystwyth University Col & lege & $\ldots$ & $\cdots$ & 140 & 297 & 437 & - & 8 & 8 & II & 15 & $47 \mathrm{I}$ & I I & 437 & 8 & I I \\
\hline & Bangor Úniversity College & $\ldots$ & $\cdots$ & $\cdots$ & I 13 & 167 & 280 & - & II & II & I 5 & IO & 316 & - & 280 & II & 15 \\
\hline I9. & Cardiff University College & 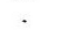 & $\cdots$ & $\cdots$ & 186 & 288 & 474 & - & 68 & 68 & 5 & 29 & 576 & $\mathbf{I}$ & 474 & 68 & II \\
\hline 20. & Totals-W & ales & $\cdots$ & $\cdots$ & 439 & $75^{2}$ & II9I & - & 87 & 87 & $3 I$ & 54 & 1363 & 12 & II 191 & 87 & 37 \\
\hline
\end{tabular}

1 Eight of these were students in training who were reading for the Teachcrs' Diploma (post-graduate).

2 Twenty-five of these were following degree courses though they had not matriculated.

eighteen will probably fall. In Wales secondary education has been organised for a greater length of time than in England, and this is probably one of the causes for the smaller percentage of day students under eighteen in the Welsh colleges.

\section{UNIVERSITY AND EDUCATIONAL INTELLIGENCE.}

CAMBridge.-At the annual general meeting of the Philosophical Society, held on Monday, October 30, the following were elected officers :-President, Prof. Sir George Darwin ; vice-presidents, Prof. Newall, Prof. Hopkinson, Prof. Wood; treasurer, Prof. Hobson; secretaries, Dr. Barnes, Mr. A. Wood, Mr. F. A. Potts ; members of council, Prof. Sir J. Larmor, Prof. Biffen, Prof. Pope, Mr. R. H. Rastall, Mr. K. Lucas, Mr. E. A. Newell Arber, Prof. Sir J. J. Thomson, Mr. J. E. Purvis, The Master of Christ's, Mr. R. P. Gregory, Dr. Cobbett, and Mr. J. W. Mercer. The names of the new members of the council are in italics.

At Christ's College, Dr. H. J. H. Fenton, F.R.S., and Prof. E. W. Brown, F.R.S., of the Yale University, have been elected honorary fellows. The same honour has been conferred at Emmanuel College on Mr. R. H. Biffen, prælector in agriculture, and on Mr. F. G. Hopkins, F.R.S., prælector in biochemistry at Trinity College, formerly fellow and tutor of Emmanuel.

T. G. Bedford has been appointed demonstrator of experimental physics, and J. A. Crowther and H. Thirkill assistant demonstrators.

The electors to the Allen scholarship give notice that they are prepared to receive applications from candidates. Any graduate of the University is eligible for the scholarNO. 2 I92. VOL. 887 ship provided that his age on the first day of the Lent term 1912 does not exceed twenty-eight years. This year the scholarship is open to candidates who propose to undertake research in any branch of study which comes within the department of any of the following special boards :medicine, mathematics, physics and chemistry, biology and geology. The emolument of the student is $250 l$., or such smaller sum as the fund, after payment of all expenses, shall be capable of providing. Candidates must send their names to the Vice-Chancellor on or before February $I$, I9I2.

The electors to the Isaac Newton studentships give notice that an election to a studentship will be held in the Lent term, 1912. These studentships are for the encouragement of study and research in astronomy (especially gravitational astronomy, but including other branches of astronomy and astronomical physics) and physical optics. The persons eligible are members of the University who have been admitted to the degree of Bachelor of Arts, and are under the age of twenty-five years on the first day of January, 1912. The studentship will be tenable for the term of three years from April 15, 1912. Candidates for the studentship are invited to send in their applications to the Vice-Chancellor between January 16 and 26, 1912 .

The special board for biology and geology gives notice that the Gedge prize will be offered for competition in the Michaelmas term, ig12. The prize will be awarded for the best original observations in physiology. The essays are to be sent to the professor of physiology not later than October I, Igr2. The examiners may require every candidate to deliver his essay in the form of a lecture.

OXFORD.-The statute exempting candidates for honours in mathematics and natural science from compulsory Greek is approaching its final stages. On Tuesday, November 7 , 